
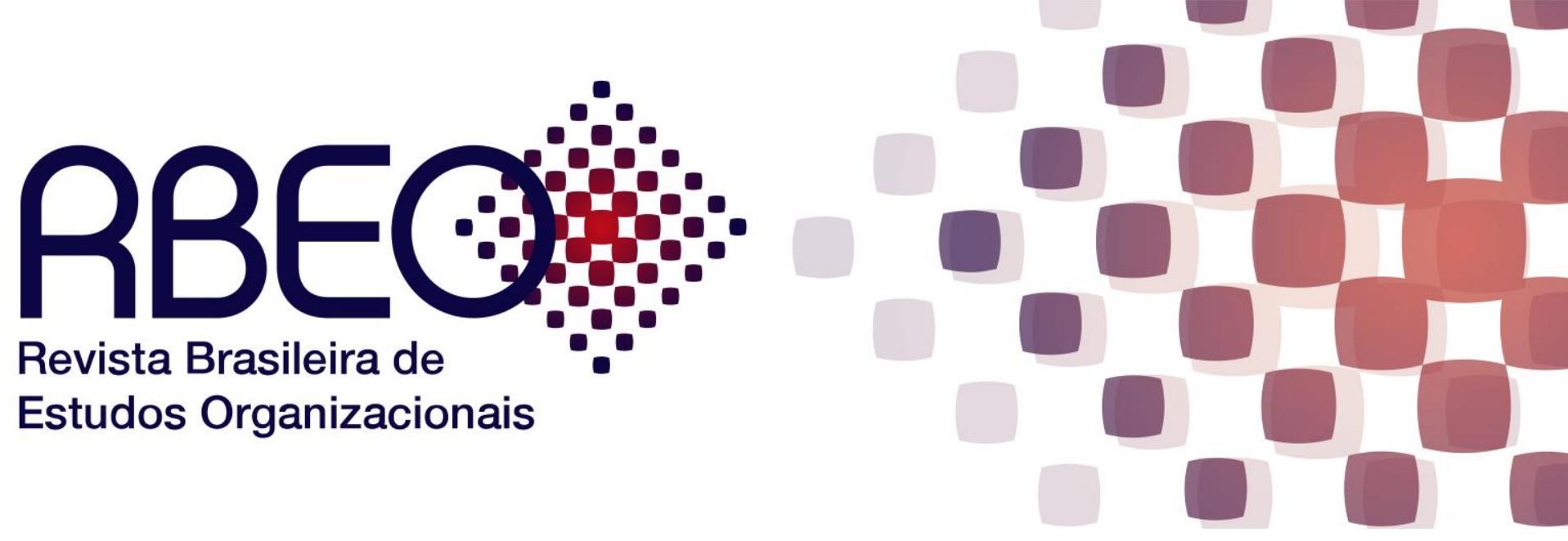

\title{
A GROUNDED THEORY COMO UMA AUXILIAR PARA COMPREENDER A (NÃO) INCLUSÃO DE DEFICIENTES NO TRABALHO
}

\author{
Eva Bessa Soares ${ }^{1}$
}

DOI: $10.21583 / 2447-4851 . r b e o .2018 . v 5 n 1.157$

\section{RESUMO}

Nesta pesquisa, buscou-se conhecer o contexto da (não) inclusão de profissionais com deficiência, a partir da metodologia da Grounded Theory, que contemplou um estudo empírico no qual foram envolvidas oito empresas de uma cidade no interior de Minas Gerais/Brasil. Os resultados apontam que tanto os profissionais com deficiências, quanto os gestores têm dificuldades nesse processo de inclusão. Assim, a Lei 8.231/91 (Lei de Cotas) vem sendo cumprida parcialmente pelas empresas estudadas. As contribuições desse artigo consistem em auxiliar no preenchimento das lacunas existentes na literatura quanto à utilização dessa metodologia para estudar a inclusão de deficientes no trabalho no campo da Administração, principalmente na gestão de pessoas, além de contribuir para a divulgação de algumas das potencialidades dessa metodologia para as pesquisas qualitativas.

Palavras chave: Grounded Theory. Inclusão de deficientes no trabalho. Lei 8.231/91 (Lei de Cotas)

\section{LA GROUNDED THEORY COMO UNA AUXILIAR PARA COMPRENDER LA (NO) INCLUSIÓN DE DEFICIENTES EN EL TRABAJO}

\section{RESUMEN}

En esta investigación, se buscó conocer el contexto de la (no) inclusión de profesionales con discapacidad, a partir de la metodología de Grounded Theory, que contempló un estudio empírico en el que participaron ocho empresas de una ciudad en el interior de Minas Gerais / Brasil. Los resultados apuntan que tanto los profesionales con deficiencias, cuanto los gestores tienen dificultades en ese proceso de inclusión. Así, la Ley 8.231 / 91 (Ley de cuotas) viene siendo cumplida parcialmente por las empresas estudiadas. Las contribuciones de este artículo consisten en auxiliar en el llenado de las lagunas existentes en la literatura en cuanto a la utilización de esa metodología para estudiar la inclusión de discapacitados en el trabajo en el campo de la Administración, principalmente en la gestión de personas,

\footnotetext{
1 Mestra em Engenharia da Produção. Doutoranda em Administração (EAESP/FGV). Professora na Universidade Federal de Ouro Preto (UFOP). Correio eletrônico: eva@deenp.ufop.br.
} 
además de contribuir a la divulgación de algunas de las potencialidades de esa metodología para las investigaciones cualitativas.

Palabras clave: Grounded Theory. Inclusión de discapacitados en el trabajo. Ley 8.231 / 91 (Ley de cuotas).

\title{
A GROUNDED THEORY AS AN AUXILIARY TO UNDERSTAND THE (NO) INCLUSION OF DISABLED PEOPLE AT WORK
}

\begin{abstract}
In this research, we sought to know the context of the (non) inclusion of professionals with disabilities, based on the methodology of Grounded Theory, which included an empirical study involving eight companies from a city in the interior of Minas Gerais / Brazil. The results indicate that both professionals with disabilities and managers have difficulties in this inclusion process. Thus, Law 8,231 / 91 (Quotas Law) has been partially fulfilled by the companies studied. The contributions of this article are to help fill the existing gaps in the literature regarding the use of this methodology to study the inclusion of people with disabilities in the field of Administration, mainly in the management of people, besides contributing to the dissemination of some of the potentialities of this methodology for qualitative research.
\end{abstract}

Keywords: Grounded Theory. Inclusion of disabled people at work. Law 8,231 / 91 (Quota Law).

INTRODUÇÃO

A sociedade tem dificuldades em lidar com a diversidade. Essa questão se revela em muitas atitudes das pessoas no cotidiano, no contexto laboral de muitas organizações e também em ações de indivíduos que vêm sendo divulgadas na mídia brasileira.

Essa dificuldade é expressa também em ações discriminatórias por parte de organizações que são representadas por gestores que manifestam resistências em contratar profissionais com deficiência. Tal situação fica mais evidente quando há necessidade de estabelecer leis para obrigar as organizações públicas e privadas a reservarem uma cota de vagas a esses profissionais e também a implantação de fiscalizações constantes para avaliar as condições do cumprimento de tais legislações.

A inclusão de profissionais com deficiência é um tema não tão recente, entretanto, ainda enfrenta barreiras, tanto por parte desses trabalhadores, quanto dos gestores de empresas de segmentos diversos.

Neste artigo, será discutida a existência da Lei de Cotas que, embora seja considerada um grande avanço, ainda não vem sendo cumprida na sua totalidade por empresas no 
interior de Minas Gerais/Brasil. Dessa forma, serão apresentadas algumas percepções de gestores e profissionais com deficiência quanto às principais dificuldades que eles têm encontrado nesse contexto.

A questão norteadora deste artigo é: quais os aspectos inerentes ao contexto da (não) inclusão de deficientes no trabalho de empresas em uma cidade do interior de Minas Gerais/Brasil? O intuito é mapear alguns desses itens a partir da ótica dos gestores e trabalhadores desse contexto. Para tal, foi utilizada a Grounded Theory que pode ser definida como uma metodologia de pesquisa constituída de um processo contínuo e sistemático de coleta e análise de dados para a geração e verificação dos resultados (GLASER e STRAUSS, 1967).

A primeira seção traz uma breve visão sobre estudos realizados no contexto brasileiro acerca da inclusão de deficientes. A segunda seção aborda a legislação brasileira para pessoas com deficiência e o acesso ao trabalho. Na terceira seção, é apresentada a Teoria fundamentada em dados (Grounded Theory), um breve resumo e alguns dos principais autores dessa metodologia. Na quarta seção, foi detalhado o percurso metodológico. Na quinta seção estão os resultados e as discussões e a sexta seção conclui o artigo.

\section{A ABORDAGEM DA INCLUSÃO DE PROFISSIONAIS COM DEFICIÊNCIAS NO CONTEXTO BRASILEIRO}

A inclusão de profissionais com deficiência no mercado de trabalho brasileiro é um tema de difícil abordagem, pois tanto os profissionais em busca de uma vaga quanto aqueles que atuam recrutando e selecionando tais profissionais para admissão enfrentam muitos desafios.

No campo da Administração no Brasil, os Estudos Organizacionais têm abordado a diversidade enfatizando as formas como vem ocorrendo a inserção no trabalho de profissionais com deficiência. Tais estudos visaram identificar as facilidades e as barreiras enfrentadas por pessoas para serem inseridas e se manterem no mercado de trabalho (HEINSKI e BIGNETTI, 2002; NERI, 2003; BATISTA, 2004; CARVALHO-FREITAS, 2007).

Para Carvalho-Freitas (2007) há algumas concepções sobre a deficiência, sendo elas: concepção espiritual da deficiência, concepção baseada nos pressupostos da normalidade, 
concepção baseada na inclusão, percepção dos benefícios da contratação, percepção do vínculo, percepção de desempenho e percepção da necessidade de treinamento na qual está amparada a ideia de que a necessidade de treinamento é uma forma de facilitar a inserção e a socialização dos profissionais com deficiência no trabalho.

Interessados em saber se as crenças dos profissionais que trabalham no contexto de inserção de deficientes no trabalho podem interferir na forma como eles atuam, Rezende e Carvalho-Freitas (2014) apontam que, embora haja atitudes diferenciadas dos profissionais de Recursos Humanos frente à inclusão, na pesquisa realizada não foi percebida nenhuma relação entre concepções de deficiência e as suas práticas inclusivas.

As crenças que as pessoas vão desenvolvendo em relação à deficiência estão também relacionadas às expressões para denominação de tais pessoas. A literatura sobre o tema revela que há certa dificuldade ao longo dos anos na adoção de um termo correto para definir as pessoas com deficiências. Para Sassaki (2003), a cada época são utilizados termos cujos significados sejam compatíveis com os valores vigentes em cada sociedade.

Desde 1960 até 2005 havia muitos termos como "inválidos", "incapacitados", "incapazes", "defeituosos", "deficientes", "excepcionais", "pessoas deficientes", "pessoas portadoras de deficiência", "pessoas com necessidades especiais", "portadores de necessidades especiais", "pessoas especiais", "pessoas com deficiência", "portadores de direitos especiais" até o termo que vem sendo usado por outros autores "pessoas com deficiência" (SASSAKI, 2003). O autor aponta que os movimentos mundiais de pessoas com deficiência discutiram quanto ao nome pelo qual essas pessoas desejam ser chamadas. Mundialmente elas definiram que querem ser chamadas de "pessoas com deficiência" em todos os idiomas. Esse termo faz parte do texto da Convenção sobre os direitos das pessoas com deficiência - comentada (2008).

Há autores que defendem que as definições não têm tanta importância, como é o caso de Finkelstain (1980), pois, para ele, a deficiência é uma construção social, uma vez que é a sociedade quem estabelece os padrões de normalidade e cria o paradoxo entre pessoas com e sem deficiência, julgando, a partir dessa atitude e enquadrando aqueles que se encaixam nesses padrões.

De acordo com o Decreto brasileiro 914/1993, pessoa portadora de deficiência é aquela que apresenta, em caráter permanente, perdas ou anomalias de sua estrutura ou 
função psicológica, fisiológica ou anatômica, que gerem incapacidade para o desempenho de atividades dentro do padrão considerado normal para o ser humano.

Para a CORDE (Câmara Técnica sobre reserva de vagas para pessoas com deficiência/Coordenadoria Nacional para a integração da pessoa portadora de deficiência), enquadram-se, como pessoa com deficiência, as seguintes categorias: deficiência física, deficiência auditiva, deficiência visual, deficiência mental e deficiências múltiplas.

No tocante ao número de pessoas com deficiência no mundo, a Organização Internacional do Trabalho (2010) aponta que elas representam $10 \%$ da população mundial, isto é, em torno de 650 milhões de pessoas, dentre as quais aproximadamente $72 \%$ estão em idade produtiva. Esses dados mostram a pertinência desta discussão proposta no presente artigo.

Mais de um bilhão de pessoas no mundo possuem alguma deficiência, dentre as quais, cerca de 200 milhões experimentam dificuldades funcionais consideráveis. Um dado relevante é que nos próximos anos, a deficiência será uma preocupação maior porque além de sua incidência vir aumentando, também há fatores como o envelhecimento e o risco maior de deficiência na população de mais idade. É preciso considerar também o aumento global de doenças crônicas, tais como diabetes, doenças cardiovasculares, câncer e distúrbios mentais (RELATÓRIO MUNDIAL SOBRE A DEFICIÊNCIA, 2011).

Os dados do Censo 2010 do IBGE (Instituto Brasileiro de Geografia e Estatística) revelam que quase 46 milhões de brasileiros, cerca de $24 \%$ da população, declararam possuir pelo menos uma das deficiências investigadas (mental, motora, visual e auditiva). Esses dados revelam que há uma parcela expressiva da população que tem algum tipo de deficiência e que merece atenção quanto à necessidade de a sociedade rever os direitos dessas pessoas se inserirem no mercado de trabalho e também usufruírem de todos os serviços sociais: saúde, cursos para capacitação profissional, além de atividades de lazer.

Ainda de acordo com os dados do Censo de 2010 do IBGE (Instituto Brasileiro de Geografia e Estatística), a deficiência visual foi a mais frequente, atingindo 35,8 milhões de pessoas com dificuldade para enxergar $(18,8 \%)$, mesmo de óculos ou lentes de contato. A deficiência visual severa (pessoas que declararam ter grande dificuldade de enxergar ou que não conseguiam de modo algum) atingia 6,6 milhões de pessoas, sendo que 506,3 mil eram $\operatorname{cegos}(0,3 \%)$. 
A dificuldade de locomoção incidia sobre 13,3 milhões de pessoas (7,0\%). A deficiência motora severa (pessoas com grande dificuldade ou incapazes de se locomover) foi declarada por 4,4 milhões de pessoas, das quais 734,4 mil não conseguiam caminhar ou subir escadas de modo algum (0,4\%). Já a deficiência auditiva acometia 9,7 milhões de pessoas $(5,1 \%)$, sendo que a deficiência auditiva severa (pessoas com grande dificuldade ou incapazes de ouvir) foi declarada por 2,1 milhões de pessoas, das quais 344,2 mil eram surdas (0,2\%). A deficiência mental ou intelectual, também considerada severa, foi declarada por 2,6 milhões de pessoas, representando 1,4\% da população.

Em 2010, a população com deficiência e que estava empregada representava $23,6 \%$ (20,4 milhões) do total de pessoas ocupadas (86,4 milhões). Das 44 milhões de pessoas com deficiência em idade ativa (10 anos ou mais), 53,8\% (23,7 milhões) não estava ocupada. Em relação ao total da população que não estava ocupada $(75,6$ milhões), a população com deficiência representava 31,3\%. Esses dados revelam que há muito a ser feito para que a população de profissionais com deficiência tenha acesso ao emprego.

Em relação à taxa de atividade por tipo de deficiência, a deficiência mental foi a que mais limitou a inserção no mercado de trabalho, tanto para homens como para mulheres (cujas taxas de atividade foram de $22,2 \%$ e $16,1 \%$, respectivamente). A deficiência visual foi a que menos influenciou na taxa de atividade, que ficou em $63,7 \%$ para os homens e $43,9 \%$ para as mulheres.

O mesmo foi observado para o nível de ocupação, que, no geral, ficou em 17,4\% para pessoas com deficiência mental e $48,4 \%$ para pessoas com deficiência visual. $40,2 \%$ das pessoas com deficiência em ocupações possuem carteira assinada. É uma informação relevante, pois estar empregado(a) não significa ter acesso aos direitos básicos dos trabalhadores(as), como o caso da carteira assinada. Esses dados revelam que em torno de 60\% dos trabalhadores(as) com deficiência em 2010 não tinham a carteira assinada.

Em se tratando de políticas sociais voltadas para as necessidades das pessoas com deficiências, Sassaki (2003) caracteriza dois modelos de interpretação da deficiência: o modelo da integração social que aborda o ponto de vista médico da deficiência e que originou as práticas sociais. Sendo que essas objetivavam melhorar a pessoa com deficiência para conviver em sociedade. O outro modelo é o da inclusão social no qual a sociedade se adapta às necessidades das pessoas com deficiência e estas buscam o seu desenvolvimento 
na sociedade. Parece ser este modelo que algumas empresas vêm seguindo, pois, ao admitirem esses profissionais, as empresas realizam adaptações (normalmente estruturais) para que possam atuar.

A sociedade brasileira está engajada para construir um contexto que reconheça, respeite e acolha com dignidade a diversidade que a constitui (SCHWARTZ e HABER, 2006). A Lei $8.213 / 91$, que não é tão recente, apesar de enfrentar muitas resistência e incompreensões, representa um avanço. Esse processo é complexo e demorado, pois implica na mudança do pensar social, das atitudes sociais e na inserção de adaptações objetivas que atendam às necessidades específicas e peculiares de todos. Assim, a empresa que contrata funcionários com deficiência deve ter um programa estruturado de adequação da sua estrutura física, recrutamento, seleção, contratação e desenvolvimento e não apenas contratar formalmente para cumprir a lei.

Nesse processo, é preciso considerar quais as reais responsabilidades do governo também, pois essa responsabilidade de incluir, no trabalho, pessoas com deficiências, não pode ser relegado apenas às empresas, mas requer diálogos interdisciplinares nos quais a sociedade, os gestores de empresas de diversos segmentos e o governo devem discutir e implantar alternativas plausíveis.

No Relatório Mundial sobre a Deficiência, há sugestões de ações nas quais deverão incluir os governos, as organizações da sociedade civil e as organizações de pessoas com deficiência (acrescentamos também a importâncias das famílias, universidades e demais instituições das quais os deficientes fazem parte) para criar ambientes facilitadores, desenvolver serviços de suporte e reabilitação, garantir uma adequada proteção social, criar políticas e programas de inclusão e fazer cumprir as normas e a legislação, tanto existentes como novas, para o benefício das pessoas com deficiência e da comunidade como um todo (RELATÓRIO MUNDIAL SOBRE A DEFICIÊNCIA, 2011).

\section{A LEGISLAÇÃO BRASILEIRA PARA PESSOAS COM DEFICIÊNCIA E O ACESSO AO TRABALHO}

No Brasil, às pessoas com deficiência é garantido o direito de acesso ao trabalho, elas são amparadas pelas Leis no $8.112 / 90$, em caso de concursos para as vagas em empregos públicos e a Lei no 8.213/9,1em caso de vagas em empresas privadas. 
Para inclusão de profissionais com deficiência no Brasil, a Lei no 8.112/90 determina a reserva de até $20 \%$ das vagas de concursos públicos na União para os profissionais deficientes. Seguindo a mesma orientação, a Lei no 8.213/91 (também denominada Lei de Cotas), em seu artigo 93, dispõe que as empresas com 100 funcionários ou mais deverão contratar pessoas com deficiência ou reabilitadas. A lei prevê que uma determinada quantidade de vagas, que varia de $2 \%$ a $5 \%$ do número total de funcionários, deve ser reservada para os referidos profissionais, sejam eles reabilitados, ou deficientes habilitados.

Cabe ressaltar que o Brasil, ao criar uma legislação, como a Lei no 8.213/91, demonstra um importante avanço e também uma sintonia com países desenvolvidos e que já possuem legislações nessa direção como a Alemanha (Severely Disabled Persons Act, 1974), os Estados Unidos (Americans with Disability Act (ADA, 1990) e o Reino Unido (Disability Discrimination Act - DDA,1995). Entretanto, há muito a ser feito, pois conduzir as empresas a cumprirem a referida legislação tem sido um grande desafio tanto aos profissionais interessados, quanto à fiscalização do Ministério Público do Trabalho.

A receptividade e adesão das empresas em relação à Lei no 8.213/91, que legisla a respeito da inclusão de deficientes em empresas privadas é sempre complexa, pois há muitos gestores que manifestam desinteresse em relação a essa temática, considerando perda de tempo, pois, segundo suas concepções, nem sempre os profissionais com deficiência apresentam desempenhos satisfatórios. Um trabalho que nos auxilia nessa discussão é o realizado por Ribeiro e Carneiro (2009) em uma das Procuradorias Regionais do Trabalho do Ministério Público do Trabalho de Belo Horizonte (Minas Gerais, Brasil). Tal pesquisa envolveu todos os processos de autuação por não cumprimento da norma legal (Lei de Cotas), conduzidos pela referida Procuradoria Regional do Trabalho no período de 20002007. Os resultados evidenciaram uma baixa adesão em relação à referida Lei e também as principais estratégias defensivas adotadas pelas empresas para contornar, protelar ou minimizar a contratação compulsória de profissionais com deficiência.

Defendemos que o cumprimento da legislação requer engajamento de gestores, do poder público e da sociedade em geral. Essa defesa é coerente com Moreira (2011) que aponta que apenas a legislação não elimina as barreiras existentes no contexto da inclusão dos profissionais com deficiências. 


\section{TEORIA FUNDAMENTADA EM DADOS (GROUNDED THEORY)}

No desenvolvimento dessa pesquisa foi utilizada a Teoria Fundamentada em dados (Grounded Theory) que pode ser definida como uma metodologia de pesquisa constituída de um processo contínuo e sistemático de coleta e análise de dados para a geração e verificação dos resultados (GLASER e STRAUSS, 1967).

A opção por essa metodologia se justifica pela lacuna de estudos no campo da Administração de Empresas sobre a inclusão de deficientes no trabalho utilizando a Teoria Fundamentada em dados (Grounded Theory), além de ela se constituir em um método coerente com o objetivo aqui proposto: conhecer o contexto da (não) inclusão de deficientes no trabalho de empresas em uma cidade do interior de Minas Gerais/Brasil, a partir da ótica dos gestores e trabalhadores desse contexto.

Ao utilizar a essa metodologia, inicia-se pela coleta de dados empíricos e permite-se que os conceitos vão emergindo para a construção da teoria. Caracteriza-se por uma metodologia flexível, mas também, conforme postulam Strauss e Corbin (2008), significativa, generalizável, reproduzível, precisa, rigorosa e verificável, critérios necessários a uma boa pesquisa.

A Teoria Fundamentada (Grounded Theory) foi desenvolvida por dois sociólogos de tradição filosófica, sociológica e de pesquisa diferentes: Barney Glasser e Anselm Strauss. Ambos possuem tradição em pesquisa qualitativa. Barney Glaser fazia análises qualitativas e percebia a necessidade de fazer comparações entre dados com o intuito de identificar, desenvolver e relacionar os conceitos (STRAUSS e CORBIN, 2008). As contribuições Anselm Strauss também estão embasadas em sua formação e foram importantes para o desenvolvimento da Teoria Fundamentada. Algumas dessas contribuições são:

\footnotetext{
a necessidade de sair a campo para descobrir o que realmente está acontecendo, a relevância da teoria, baseada em dados, para o desenvolvimento de uma disciplina e como base para a ação social, a complexidade e a variabilidade dos fenômenos e das ações humanas; a crença de que as pessoas são atores que assumem um papel ativo para responder a situações problemáticas [...] (STRAUSS e CORBIN, 2008, p. 22).
}

Strauss e Corbin (2008), ao discorrerem sobre a objetividade, apontam as técnicas analíticas desenvolvidas por eles para auxiliar a controlar os desvios na análise: pensar comparativamente, baseando incidente por incidente nos dados; obter pontos de vista 
múltiplos; reunir dados sobre o mesmo evento ou fenômeno de diferentes maneiras (entrevistas, observações e relatórios escritos); ocasionalmente verificar com os(as) informantes as suposições e as hipóteses em relação aos dados. Esse procedimento objetiva a avaliação se elas estão de acordo com as experiências dos(as) participantes.

No tocante à questão de pesquisa, Strauss e Corbin (2008) postulam que ela deve ser estruturada antes de iniciar o processo de investigação, de forma que garanta flexibilidade e liberdade para explorar um fenômeno em profundidade. Strauss e Corbin $(2008$, p. 56) enfatizam que "a ideia não é adesão rígida aos procedimentos, mas sim, uma aplicação fluida e habilidosa".

A Teoria Fundamentada em dados (Grounded Theory) vem sendo utilizada no contexto brasileiro, há alguns anos. Citam-se como autores de destaque que discutem as características desse método, sua história, as principais obras de referência, além de outras informações relacionadas à sua aplicabilidade no campo da Administração: Bandeira-deMello e Garreau (2009), Petrini e Pozzebon (2009), Hopfer e Lima (2008), Bandeira-de-Mello e Cunha (2006), além de outros autores.

Há também pesquisas relevantes com o propósito de conhecer o conjunto de estudos que têm sido desenvolvido no campo da Administração em um determinado período, como a pesquisa bibliométrica e de estado da arte. A partir da consulta de 48 artigos publicados nos eventos da Associação Nacional dos Programas de Pós-Graduação em Administração (ANPAD), no período de 1997 a 2011, Zanin, Bach e Walter (2012) apontaram que ela está em processo de difusão entre os pesquisadores da área da Administração do Brasil. Nessa pesquisa, as autoras apontam que o tema mais estudado foi a Grounded Theory como uma abordagem de pesquisa interpretacionista em Administração. Também Bianchi e Ikeda (2008, p. 231) interessaram-se pela discussão acerca da utilização desse método na Administração e concluem que ela "é complexa, rica e poderosa, sendo bastante aplicável na administração, no contexto social".

Outro estudo relevante nessa perspectiva é o de Castro e Machado (2017) que buscaram responder à questão: "Após quase 50 anos de utilização nas ciências sociais, como estão os resultados das pesquisas feitas por meio da Grounded Theory no Brasil?" Os autores analisaram 20 artigos científicos publicados, entre os anos 2000 e 2014, em periódicos científicos nacionais com classificação A1 e B1 e nos anais dos congressos da Associação 
Nacional de Pós-Graduação e Pesquisa em Administração (ANPAD), que indicaram a utilização do método no desenvolvimento de pesquisa empírica. Os resultados sugerem que os autores utilizaram o método de diversas formas e em todos os artigos analisados não houve a produção de uma teoria propriamente dita, entretanto produziram aproximações teóricas.

A literatura (Zanin, Bach e Walter (2012); Bandeira-de-Mello e Garreau (2009); Petrini e Pozzebon (2009); Hopfer e Maciel-Lima (2008); Bianchi e Ikeda (2008); Bandeira-de-Mello e Cunha, 2006 e outros) revela a ampla utilização da Grounded Theory no campo da Administração e o esforço dos pesquisadores para a divulgação desse método.

Nessa pesquisa, a utilização da Grounded Theory foi a abordagem proposta por Strauss e Corbin (2008). A justificativa para a sua utilização se ateve a duas das premissas desse método, sendo que a primeira está relacionada à sua possibilidade de proporcionar um equilíbrio entre a teoria existente e as análises e comparações dos dados que vão emergindo. A outra está relacionada à proposição que, "para produzir resultados úteis, as complexidades do contexto organizacional devem ser incorporadas no entendimento do fenômeno" (PETRINI e POZZEBON, 2009, p. 4). Compreendemos que o contexto da (não) inclusão dos profissionais com deficiência no mercado de trabalho é complexo, requerendo investigações e proposição de diálogos dos mais diversos possíveis.

\section{PERCURSO METODOLÓGICO}

Após a revisão da literatura, foram elaborados três questionários: um para entrevista com profissionais em busca de trabalho, outro para aqueles empregados e outro para gestores de empresas. Depois, procedeu-se ao envio de convites às empresas com mais de 100 funcionários que estão localizadas em uma cidade (e também adjacências) do interior de Minas Gerais. Foram feitos contatos também com uma instituição filantrópica que cadastra profissionais com deficiência que estão em busca de trabalho. O objetivo foi buscar contato com esses profissionais e convidá-los para participarem dessa pesquisa.

As questões semiestruturadas dos questionários direcionados aos gestores visaram conhecer o contexto da inclusão dos deficientes em empresas localizadas na referida cidade; mais especificamente, pretendeu abordar as questões organizacionais gerais referentes à 
gestão de pessoas: admissão, treinamento, retenção dos profissionais deficientes e abordaram aos temas: a) percentual de profissionais com deficiência que havia no quadro de funcionários da empresa no momento da pesquisa; b) se ela tem conseguido cumprir a cota estabelecida pela Lei $8213 / 91$; c) quais as dificuldades a empresa têm encontrado para a contratação desses profissionais, qual o perfil de profissionais com deficiência ela tem mais facilidade de contratar; d) como tem sido o processo de gestão desses profissionais; e) qual o perfil que ela tem mais dificuldade e, por último, e) como a Universidade Federal de Ouro Preto (UFOP) poderá auxiliá-la nesse processo.

As questões semiestruturadas dos questionários direcionados aos profissionais empregados abordaram aos temas: a) cargo, escolaridade, qualificações, tarefas que desempenham (facilidades e dificuldades encontradas); b) se conhecem a Lei 8213/91; c) como é para eles estarem empregados; d) como a Universidade Federal de Ouro Preto (UFOP) poderá auxiliá-la nesse processo de inclusão.

As questões semiestruturadas dos questionários direcionados aos profissionais em busca de vagas abordaram aos temas: a) há quanto tempo estão em busca de trabalho (escolaridade, qualificações em geral); b) se conhecem a Lei $8213 / 91$; c) as principais percepções sobre essa busca de trabalho (facilidades, desafios); d) como a Universidade Federal de Ouro Preto (UFOP) poderá auxiliá-la nesse processo de inclusão.

O levantamento de dados ocorreu nos anos de 2015 e 2016, em uma cidade do interior de Minas Gerais/Brasil. Adotou-se como critério para convidar a participar dessa pesquisa, apenas as empresas que possuem mais de 100 funcionários. Assim, foram convidadas, via e-mail, vinte e oito empresas que estão nessa cidade e também em regiões próximas. Apenas oito manifestaram interesse.

O segmento dessas empresas é variado: supermercado, metalúrgico, hospitalar e comércio de peças automotivas. Ocorreram visitas a essas empresas para conhecer os postos de trabalho e entrevistar os empregadores (chefias) e/ou profissionais de Recursos Humanos e os referidos profissionais.

O número de empregados com deficiências entrevistados foi vinte e dois e todos eles estavam atuando nos quadros dessas empresas. Participaram também da pesquisa dezoito profissionais com deficiência que estavam desempregados e em busca de uma vaga de 
emprego naquele momento. $\mathrm{O}$ contato da pesquisadora com eles foi através daqueles que estavam empregados.

Depois de gravadas, as entrevistas foram transcritas e analisadas, por análise temática de conteúdo, a partir da categorização dos temas que apareceram nas entrevistas (STRAUSS e CORBIN, 2008). Conforme orientações desses autores, as etapas foram ocorrendo de forma alternada: coleta de dados, análises, novas coletas e assim sucessivamente. Foram realizadas as etapas de análises sugeridas por esses autores:

a) Microanálise que é a fase na qual o(a) analista/pesquisador(a) ouvirá cuidadosamente o que e como as pessoas entrevistadas estão dizendo sobre determinado conteúdo. Essa etapa permite aos pesquisadores examinarem as suposições sobre os dados.

b) Codificação aberta: nessa etapa, foi realizada a codificação linha por linha. Houve a identificação de conceitos e, à medida que eles foram se acumulando, foram sendo agrupados "sob termos explicativos mais abstratos, que são as categorias (STRAUSS e CORBIN, 2008, p. 115)."

c) Codificação axial: sob as considerações de Strauss e Corbin (2008), nessa fase, muitas categorias são identificadas e algumas delas pertencem a um fenômeno, enquanto outras (que se tornarão subcategorias) referem-se a condições, ações/interações ou consequências. Essas distinções deverão ser feitas pelo(a) pesquisador(a). Foi possível a redução dos conceitos.

Strauss e Corbin (2008) sugerem a elaboração de um esquema que possa ser usado para classificar e organizar as conexões emergentes. A esse esquema organizacional, os autores chamam de paradigma e detalham "o paradigma não é nada além de uma perspectiva assumida em relação aos dados, outro ponto de vista analítico que ajuda a reunir e a ordenar os dados sistematicamente, de forma que estrutura e processo sejam integrados" (STRAUSS e CORBIN, 2008, p. 128).

Nosso paradigma está representado na Figura 1. Os componentes desse paradigma são: há condições (uma forma conceitual de agrupar respostas às questões por que, onde, de qual forma e quando); ações/interações (representadas pelas questões: quem e como) que surgem sob essas condições. Elas são respostas estratégicas ou rotineiras das pessoas ou grupos às questões e problemas. Por último estão as consequências que são os resultados das ações/interações (representadas por questões do tipo o que acontece como resultado 
A Grounded Theory como uma auxiliar para compreender a (não)inclusão de deficientes... Eva Bessa Soares

RBEO, v. 5, n. 1, p. 97-122, jun. 2018.

dessas ações/interações ou da falha de pessoas ou grupos em responder às situações através de ações/interações, que constituem um resultado importante em si mesmo).

d) Codificação seletiva: Etapa na qual iniciaram os processos de integrar e refinar as categorias. A partir da dessas etapas, os dados começam a se transformar em teoria. Ocorreu a seleção de "uma categoria central" (STRAUSS e CORBIN, 2008, p. 145).

Ressalta-se que a operacionalização da Grounded Theory é um processo trabalhoso e, embora haja uma vasta literatura com um significativo esforço de autores para detalhar as etapas e facilitar o caminho aos (às) pesquisadores (as) iniciantes, o percurso ainda é bastante complexo, cheio de incertezas e com idas e vindas aos dados e à literatura. Entretanto, tais observações não objetivam desencorajar aqueles (as) que pretendem investir nessa metodologia. Embora seja difícil, é um caminho que possibilita muitas descobertas e novos aprendizados.

Essas etapas permitiram emergir a categoria central e as subcategorias a ela relacionadas, conforme a Figura 1.

\section{RESULTADOS E DISCUSSÕES}

Strauss e Corbin (2008) sugerem que, após as etapas de codificações, ocorra a identificação de uma categoria central, de possíveis subcategorias e das relações entre elas, nessa perspectiva, para explicar o tema "quais as questões inerentes ao contexto da (não) inclusão de deficientes no trabalho de empresas em uma cidade do interior de Minas Gerais/Brasil?" as relações estão detalhadas na Figura 1. 


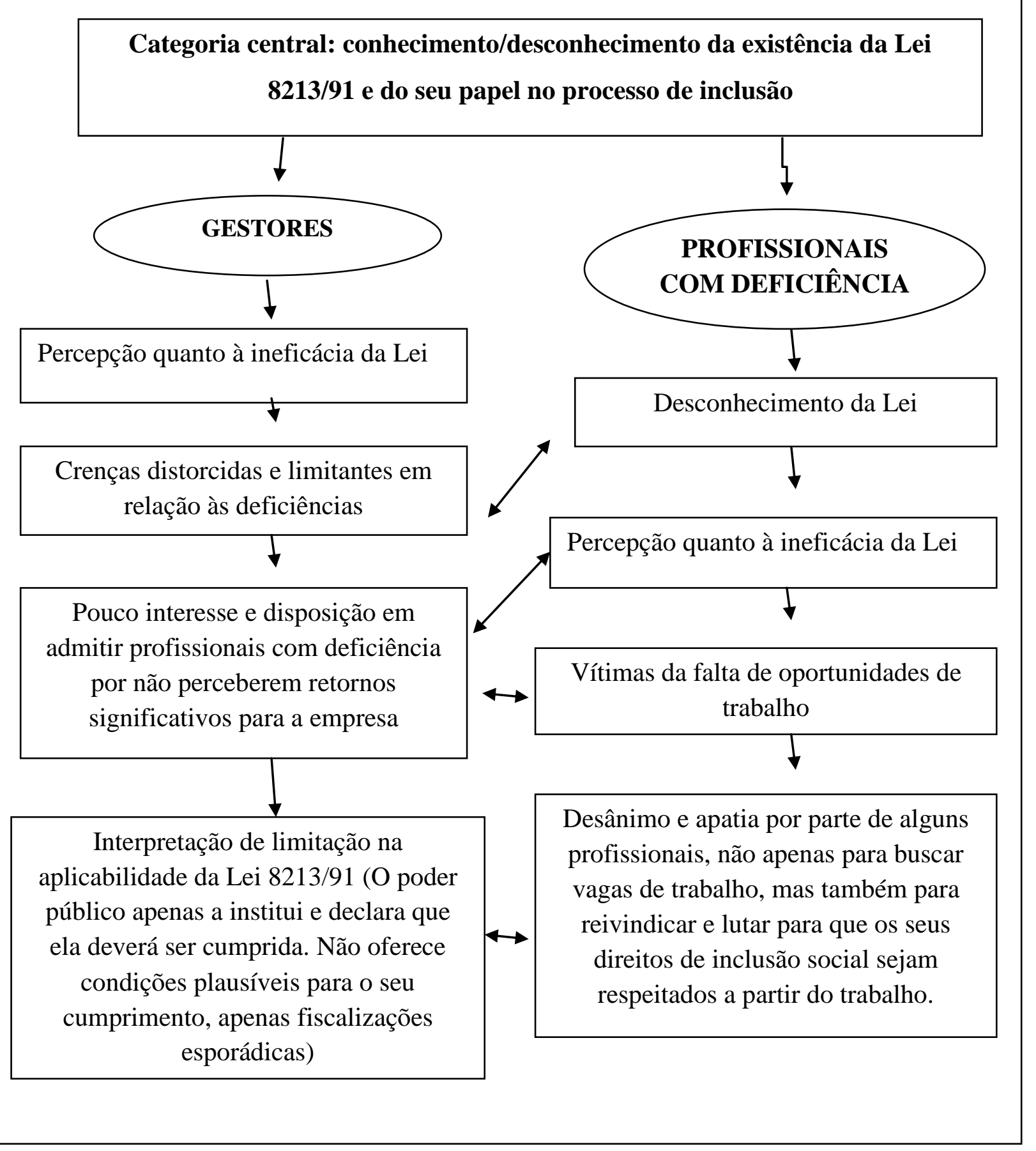

Figura 1: Categoria central e as relações com as subcategorias

Fonte: Elaborada pela autora a partir dos dados coletados nas entrevistas

A nossa categoria central foca a questão do conhecimento/desconhecimento da existência da Lei 8213/91 e do seu papel no processo de inclusão, sendo o centro da nossa discussão. Quando analisamos o ponto de vista dos gestores, a partir desse ângulo, há aqueles que percebem tal Lei como ineficaz, pois estabelece parâmetros superficiais para a 
inclusão, não dando apoios a empresas quanto à solução de inúmeros problemas que elas enfrentam para cumpri-la.

Há também gestores que não a conhecem, não sabem quais as deficiências são citadas no escopo dessa Lei e possuem uma visão muito distorcida quanto à deficiência e possibilidade de reabilitação de pessoas que sofreram acidentes.

Esses percebem todos os deficientes como iguais, julgando-os como incapacitados ao trabalho. Além desse grupo de gestores, há também outros que, embora não tenham essa interpretação da deficiência, manifestam pouco interesse e disposição em admitir profissionais com deficiência por não perceberem retornos significativos para a empresa.

Em síntese, não são todos os gestores entrevistados que percebem a Lei 8213/91 como positiva e com um potencial para cumprir um direito básico, de inclusão social através do trabalho dos profissionais com deficiências. E também não se percebem como responsáveis por participarem nesse processo.

Essas questões nos levam a inferir que um dos principais desafios enfrentados pela gestão de pessoas nesse contexto é perceber o seu real papel na inclusão dos profissionais com deficiência, depois desenvolver, implantar e gerenciar um programa amplo de empregabilidade que garanta direito de oportunidades a todos, cujo foco seja o potencial dos profissionais e não o tipo de deficiência que eles apresentam.

Esses dados são coerentes com os achados de Ribeiro e Carneiro (2009) quanto à baixa receptividade e adesão dos gestores quanto ao cumprimento da referida Lei.

Quanto aos profissionais com deficiência empregados e desempregados, há alguns que desconhecem a existência da Lei $8213 / 91$ e outros que a conhecem muito superficialmente. Esse fenômeno lhes causa uma percepção quanto à ineficácia da referida Lei, de sentimento e posicionamento como vítimas da falta de oportunidades de trabalho, além de desânimo e apatia por parte de alguns profissionais, não apenas para buscar vagas de trabalho, mas também para reivindicar e lutar para que os seus direitos de inclusão social sejam respeitados a partir do trabalho.

Das oito empresas participantes, nenhuma estava com a cota, que é estabelecida pela Legislação, preenchida no momento da pesquisa. As principais dificuldades apontadas pelos empregadores/ gestores de Recursos Humanos foram os processos que envolvem o recrutamento, a seleção e o treinamento desses profissionais. Em linhas gerais, eles 
afirmaram que tais profissionais, dificilmente, buscam as empresas para deixar os currículos e aguardar uma oportunidade de trabalho.

O recrutamento tem sido feito através de anúncios em rádios e jornais locais, faixas nas proximidades das instalações das empresas e também a partir de indicação de funcionários dessas empresas. Mesmo assim, segundo esses gestores, ainda é muito difícil aparecer candidatos com qualificações suficientes. A seleção tem sido complexa, pois, quando aparecem candidatos interessados, normalmente não preenchem os requisitos necessários, pois lhes falta qualificação técnica e comportamental.

Os dados revelaram que há situações nas quais, as empresas contratam funcionários com deficiências para cumprir a cota, sem que o candidato atenda às necessidades da empresa. Depois, as chefias ficam na expectativa que, após passarem por atividades de treinamento, o profissional conseguirá adaptar-se ao cargo. Esses achados são coerentes com aqueles de Ribeiro e Carneiro (2009) que encontraram estratégias de empresas quanto ao cumprimento da referida Lei. No entanto, a principal atitude dos gestores entrevistados está relacionada à admissão e encaminhamento aos cargos com tarefas excessivamente repetitivas e rotineiras, nas quais os profissionais com deficiências revelam dificuldades para adaptação e não percebem perspectivas de melhorias e evolução para possíveis promoções a outros cargos. A rotatividade é alta porque, em algumas situações são eles quem solicita o desligamento da empresa.

No entanto, os gestores têm encontrado dificuldade para ministrarem tais treinamentos, principalmente àqueles denominados deficientes mentais leves (pessoas com deficiência cognitiva), devido à grande dificuldade de aprendizagem que eles apresentam. Assim, a retenção deles nas empresas também se torna complexa. Normalmente eles são demitidos após os três primeiros meses da admissão, considerado período de experiência. Um gestor apontou que essa Lei é "para inglês ver" (no sentido de ineficaz), pois "o próprio governo sabe que as pessoas com deficiência não são produtivas. Levam à perda de tempo da empresa." Outro fator citado foi o alto investimento de tempo dispendido para tais treinamentos e nem sempre há um retorno para o processo produtivo. Em linhas gerais, os gestores apontam a alta rotatividade desses profissionais, considerando a dificuldade de adaptação à rotina do trabalho. 
Essa questão da necessidade de treinamento, que foi defendida pelos gestores entrevistados, é coerente com a concepção abordada por Carvalho-Freitas (2007) na qual, segundo a autora há percepção da necessidade de treinamento: ampara-se na necessidade de treinamento como forma de facilitar a inserção e a socialização dos profissionais com deficiência no trabalho.

Quando os gestores foram questionados sobre quais os perfis de profissionais deficientes eles teriam mais facilidade para contratar, as respostas variaram em função das características dos processos produtivos das empresas. Diversificando, desde o deficiente físico que não seja cadeirante (1 empregador), o deficiente visual (4 empregadores), até o deficiente mental leve ( 3 empregadores). E quanto ao perfil que apresenta maior dificuldade, apontaram o cadeirante devido às estruturas físicas atuais das empresas e também pela escassez de recursos financeiros para realização de reformas para receber profissionais cadeirantes.

Um gestor afirmou "eu não vou mudar a minha empresa inteira para receber um ou dois funcionários que usam cadeiras de rodas. Não é preconceito. É um gasto alto com possibilidade mínima de retorno, entende?" (Verbalização espontânea colhida em entrevista. Gestor A).

Ao serem questionados sobre como a Universidade Federal de Ouro Preto (UFOP) poderá auxiliá-los e aos profissionais com deficiências nesse processo de inserção, os gestores foram unânimes em pontuar a necessidade de auxílio no recrutamento (através de um espaço para recepção de currículos e divulgação de vagas) e na capacitação técnica e comportamental deles. Essas questões também foram pontuadas pelos profissionais empregados e pelos desempregados.

Os entrevistados percebem a Universidade como um órgão público que pode prestar um serviço útil para favorecer a inclusão de profissionais com deficiência no mercado de trabalho em questão. É preciso avaliar também qual será a relação da Universidade com as empresas quanto a esse auxílio nos treinamentos. Normalmente, os trabalhadores com deficiência são admitidos sem experiências e as empresas precisam treiná-los para que eles desempenhem bem as funções, entretanto, nem todos que são treinados permanecem por muito tempo nas empresas, pois pedem demissão. A partir do ponto de vista de alguns gestores, essa questão gera gastos relevantes, pois a rotatividade dessa população é muito 
alta. No entanto, essa questão não poderá ser adotada como uma transferência de responsabilidade para a Universidade, pois os treinamentos de pessoas devem ser ministrados pelas próprias empresas.

Em se tratando de adesão à Lei $8.213 / 91$, foi percebido um relativo interesse dos gestores entrevistados, no entanto, há circunstâncias nas quais há estratégias para burlá-la. Um exemplo é uma prática comum que consiste em anunciar uma vaga para profissional com deficiência no SINE (Sistema Nacional de Emprego) durante um determinado período. Não aparecem candidatos, normalmente porque as exigências são altas. A empresa solicita ao SINE um documento que comprove que ela anunciou a vaga, aguardou aparecer candidatos, mas não apareceram. Esse documento é guardado para apresentar à fiscalização do Ministério Público do Trabalho, sendo uma forma de a empresa dizer que tentou cumprir a norma (Lei 8.213/910), mas não apareceram candidatos. No entanto, depois de determinado período, a vaga é preenchida por um profissional sem deficiência e com menos exigências.

Foi percebida também uma distorção quanto ao entendimento do que é deficiência. Alguns gestores não sabem que há muitos tipos e graus de deficiências e que elas precisam ser avaliadas e consideradas em relação às exigências impostas nas suas vagas de trabalho. Um gestor verbalizou: "acho que o deficiente deve trabalhar em hospital. Lá sim, tem pessoas que o ajudam a trabalhar. Uma pessoa assim tem que ter alguém ajudando o tempo todo. Só médico consegue fazer isso. Aqui numa metalúrgica não tem jeito. Não dá tempo." (Verbalização espontânea colhida em entrevista. Gestor B).

As respostas dos vinte e dois profissionais com deficiências, empregados nas oito empresas, trazem os seguintes dados: a idade varia de 28 a 70 anos de idade (a maioria está na faixa etária de 30 a 38 anos); a escolaridade varia do ensino fundamental incompleto ao ensino médio completo, sendo que apenas dois se enquadram nessa última escolaridade. Quanto aos tipos de deficiência, a maioria (16 pessoas) possui deficiência física (devido a paralisia infantil em membros inferiores e/ou superiores ou devido a acidentes de trabalho em empresas nas quais eles trabalharam anteriormente). No entanto, há 3 profissionais com deficiência mental leve (ou deficiência intelectual). Dos entrevistados, 2 possuem deficiência auditiva e 1 deficiência visual. 
No tocante aos cargos ocupados: o mais velho, com 70 anos ocupa o cargo de fiscal há 9 anos. Os demais variam de embalador de mercadorias, arquivista, auxiliar de limpeza, auxiliar de serviços gerais, jardineiro, auxiliar de recepção. $O$ tempo varia de 9 anos (apenas 1) até 7 meses. A maioria está com 2 anos no cargo. Todos estão na segunda ou terceira empresa, ou seja, essa não é a primeira oportunidade de trabalho.

Ao serem questionados como é para eles estar trabalhando, as respostas foram positivas e manifestadas em frases como: "eu sou capaz", "é muito bom porque tenho minha própria renda", "eu aprendo muito aqui", "sinto satisfação porque trabalhar é bom". Todos responderam positivamente também quanto à recepção das chefias e colegas atuais em relação a eles, no entanto, ao serem questionados sobre qual a percepção que eles tem acerca do contexto atual da inclusão de pessoa com deficiência em empresas, as respostas foram negativas. Relataram que sofrem muito preconceito e que, conseguir a vaga atual foi muito difícil, pois passaram por outras empresas, enfrentaram muitas entrevistas, foram muitas tentativas até serem aprovados na empresa atual.

Em se tratando de um possível auxílio da Universidade Federal de Ouro Preto (UFOP) nesse processo de inclusão, a maioria sugeriu que ela ofertasse cursos como: informática, atendimento ao cliente, relações humanas e outros, pois eles têm grande interesse em mudar de cargo (serem promovidos).

Fica evidente nas verbalizações desses profissionais a importância do trabalho para dar sentido às suas vidas. Embora haja todas as barreiras relatadas, eles se percebem vencedores e capazes de irem além do que já conquistaram até o momento da pesquisa.

Os dezoito profissionais com deficiência que estão desempregados e em busca de trabalho tem idade entre 20 a 52 anos (a maioria também está na faixa etária de 30 a 35 anos). O grau de escolaridade varia de ensino fundamental incompleto até o ensino médio completo ( 5 dos entrevistados encaixam nessa escolaridade). 0 tipo de deficiência também variou de deficiência física (9), deficiência auditiva (5) e deficiência visual (4). Apenas um, com 20 anos de idade, nunca trabalhou.

Quanto às ocupações anteriores, elas variam: carpinteiro, mecânico, vigia, auxiliar de serviços gerais, frentista de posto de gasolina, recepcionista, telefonista. O tempo de desemprego variou de 2 anos e seis meses até 6 anos. Todos estão em busca de trabalho e deixaram currículo em empresas. As dificultadas encontradas são preconceito e também 
àquelas relacionadas ao acesso, pois as estruturas físicas das empresas impedem a livre acessibilidade de pessoas com deficiências física e visual. Eles vivem com as famílias e nenhum dos entrevistados recebe auxílio financeiro do governo.

Quanto aos conhecimentos acerca da Lei $8.213 / 91$ pelos profissionais com deficiência, dois dos que estão empregados e cinco dos desempregados revelaram um total desconhecimento. Esse fenômeno os dificulta lutar pelos seus direitos, pois não tem como batalhar para que essa Lei seja cumprida no contexto no qual essas pessoas estão inseridas, sendo que elas sequer sabem da existência da Lei.

Fica também mais uma reflexão: como o poder público, as universidade, a sociedade em geral pode atuar para ampliar a divulgação da referida lei. Sobre essa questão, um profissional afirmou "nunca ouvi falar da Lei que você está me perguntando. Já trabalhei uma vez porque meu tio arrumou a vaga para mim. Minha mãe é que fala que eu tenho que trabalhar e ajudar ela. Eu gosto de ficar na rua, com os colegas". (Verbalização espontânea coletada em entrevista. Profissional I). Demonstra tratar-se de uma pessoa que desconhece os seus direitos de ser incluído no trabalho.

Outro profissional verbalizou "seria bom se o governo ajudasse a gente conseguir trabalho. As empresas daqui não estão nem ai para a gente não" (Verbalização espontânea coletada em entrevista. Profissional B). Esse também revela desconhecimento quanto á existência de uma Lei há 27 anos que garante (ou deveria garantir) os seus direitos de inclusão.

Ao avaliarem o atual contexto da inclusão, os profissionais com deficiência relatam que precisa melhorar muito, haja vista, o tempo que eles estão desempregados. Eles alertam que ainda há muito preconceito na sociedade em geral. Sobre esse tema, há estudos (Marques, 2001; Popovich et al., 2003; Quintão, 2005) que nos auxiliam a refletir sobre como a sociedade ainda percebe essas pessoas, sendo essa uma das barreiras para ampliar o leque de inclusão em todas as esferas.

Sugerem que a Universidade ofereça cursos gratuitos de capacitação, pois eles não têm condições financeiras para buscá-los em outras instituições e também que ela trabalhe junto com as empresas, conscientizando-as a respeito da necessidade de inclusão desses profissionais, isto é, abrindo vagas e Ihes dando oportunidades. Dois dos entrevistados apontaram que as famílias não os apoiam na busca de vagas de emprego, e que forçam para 
que eles fiquem dentro de casa. Parece que há, por parte das famílias, um sentimento de vergonha e também superproteção quanto ao familiar com deficiência. Essa questão é mais uma barreira que essas pessoas ainda precisam transpor.

Quanto aos modelos propostos por Sassaki (2003) a partir dos quais a sociedade considera a deficiência, parece que as empresas estudadas ainda não estão conscientes do papel delas em promover adaptações para que os profissionais com deficiência desenvolvam seus potenciais. Dessa forma, percebe-se que o contexto estudado ainda carece de discussões em um nível mais abrangente, no qual o poder público, gestores e a sociedade se proponham a discutir alternativas práticas para que a inclusão dos referidos profissionais seja viabilizada.

A implantação de um programa abrangente parece complicada, no entanto, ela garante que os esforços despendidos na contratação não sejam desperdiçados, e aumente os índices de retenção. Se a pessoa com deficiência tiver atribuições claras e definidas e receber treinamento adequado para desenvolvê-las, ela terá responsabilidades e será produtiva como os outros funcionários. É um ganho tanto para o empregado, quanto para o empregador (SCHWARTZ e HABER, 2006).

\section{CONCLUSÃO}

A Grounded Theory permitiu identificar categorias e subcategorias que auxiliaram na compreensão do fenômeno "quais as questões inerentes ao contexto da (não) inclusão de deficientes no trabalho de empresas em uma cidade do interior de Minas Gerais/Brasil?"

Foi possível identificar algumas questões a partir da ótica dos gestores, trabalhadores com deficiências e também de profissionais com deficiência que estão desempregados e em busca de uma vaga de trabalho.

Os dados apresentados nessa pesquisa revelam que, no contexto estudado, ainda faltam informações quanto ao tema pesquisado. A eficácia da referida Lei requer, não apenas nessa cidade do interior de Minas Gerais, mas também em outras regiões, maior diálogo do poder público (principalmente ampla divulgação à sociedade) com os gestores, com as famílias, com as associações de deficientes e também com esses profissionais. 
Dentre as contribuições desse artigo há também a possibilidade de fazer emergir reflexões quanto às possíveis ações práticas que os gestores poderão adotar nesse contexto para enfrentar os desafios que essa Lei impõe às organizações e também, independentemente dessa legislação, fazer valer o direito básico desses profissionais que é o acesso ao trabalho.

Os dados encontrados nessa pesquisa reforçam o que a literatura demonstra: o grau de escolaridade das pessoas com deficiência é baixo. Consequentemente, as empresas lhes encaminham aos cargos e também salários de níveis mais inferiores. Muitos profissionais deficientes não conseguem reconhecer o seu potencial, necessitando assim de auxílio para reconhecerem-se como sujeitos de mudança de suas realidades.

As empresas precisam amadurecer no quesito relacionado a refletirem sobre as diversidades e avaliarem as melhores maneiras de fornecerem oportunidades de trabalho (sem aumentar propositalmente as exigências para ocupação de cargos em seus quadros de profissionais), e preparar o ambiente tanto físico, a partir de adaptações estruturais, quanto psicossocial para receber essas pessoas, dando-lhes oportunidades coerentes com suas capacidades técnicas, não Ihes menosprezando a partir do encaminhamento a atividades simplistas e rotineiras, mas auxiliando-os a reconhecerem enquanto pessoas capazes de promoverem mudanças em seus contextos atuais.

O setor de Recursos Humanos tem muitos desafios nesse contexto, pois, cabe-lhe também desenvolver as atividades para a inclusão de profissionais com ou sem deficiência na empresa. Esse setor, quando cumpre as exigências da diretoria, aumentando o nível dos quesitos para contratação de profissionais com deficiência cria alternativas dificultadoras, se não impeditivas, para a inserção de tais profissionais. Uma sugestão para esse setor seria buscar meios de auxiliar os referidos profissionais a se qualificarem dentro da empresa, após a admissão deles. Para que as suas ações sejam efetivas, esse setor precisa também buscar parcerias com os demais setores da empresa, pois os funcionários contratados irão atuar não apenas no setor de Recursos Humanos, mas em toda a empresa.

Coerente com a literatura apresentada nesse artigo, os dados encontrados nesse estudo demonstram que trabalhadores com deficiências e gestores ainda enfrentam muitos desafios para inclusão deles nos contextos das empresas estudadas. 
A lei de Cotas completa 27 anos em 2018 e surgiu com a proposta de promover a igualdade de oportunidades no contexto laboral, dando oportunidades para que estas pessoas sejam inseridas na primeira oportunidade de trabalho ou voltem a fazer parte da comunidade produtiva e, para isso, o papel das empresas (como geradoras de empregos) é muito relevante. No entanto, nos anos de 2016 e 2017 ainda encontrarmos um quadro de despreparo e desinteresse acerca dessa temática, além do enfrentamento de muitas dificuldades quanto ao seu cumprimento. É sinal de que ainda falta integração e diálogo do poder público com os gestores e a sociedade em geral.

Uma sugestão de agenda para próximas pesquisas é que deverá abranger mais empresas, tanto pequenas, quanto grandes, em outras cidades para identificar as dificuldades que seus gestores vêm enfrentando nesse contexto. As discussões devem ser ampliadas e o debate cada vez mais envolver universidades, gestores, poder público, os profissionais com deficiências e a sociedade em geral, para que esses trabalhadores tenham os seus direitos respeitados e possam mostrar seus potenciais criativos e produtivos.

\section{REFERÊNCIAS}

A CONVENÇÃO SOBRE DIREITOS DAS PESSOAS COM DEFICIÊNCIA COMENTADA / Coordenação de Ana Paula Crosara Resende e Flavia Maria de Paiva Vital. Brasília: Secretaria Especial dos Direitos Humanos. Coordenadoria Nacional para Integração da Pessoa Portadora de Deficiência, 2008. Disponível em https://www.governodigital.gov.br/documentos-earquivos/A\%20Convencao\%20sobre\%20os\%20Direitos\%20das\%20Pessoas\%20com\%20Defici encia\%20Comentada.pdf. Acesso em 29/07/2017.

BANDEIRA-DE-MELLO, R GARREAU, L. How to develop creativity in grounded theory? Epistemological choices and operational strategies in the quest for creativity. In: ENCONTRO DE ENSINO E PESQUISA EM ADMINISTRAÇÃO E CONTABILIDADE - EnEPQ, 2, 2009, Curitiba. Anais... Curitiba-PR: ANPAD, 2009.

BANDEIRA-DE-MELLO, R. e CUNHA, C. J. C. A. Grounded theory. In: GODOI, C. K.; BANDEIRADE-MELLO, R.; SILVA, A. B. Pesquisa qualitativa em estudos organizacionais: paradigmas, estratégias e métodos. São Paulo: Saraiva, 2006.

BATISTA, C. A. M. Inclusão: construção na diversidade. Belo Horizonte: Armazém de Ideias, 2004. 
BIANCHI, E. M. P. G. e IKEDA, A. A. Usos e Aplicações da Grounded Theory em Administração. Revista Gestão.Org - Volume 6 - Número 2 - p. 231-248, 2008.

BRASIL. Lei no 8213, de 24 de julho de 1991. Novo Código Civil Brasileiro. Legislação Federal. sítio eletrônico internet - http://www.planalto.gov.br. Acesso em 23/08/2014.

CARVALHO-FREITAS, M. N.; MARQUES, A. L. A Diversidade através da História: a Inserção no Trabalho de Pessoas com Deficiência. O\&S - v.14 - n.41 - Abril/Junho, 2007.

CASTRO, A. R. e MACHADO, L. Grounded Theory: uma análise da produção científica brasileira em Administração no período de 2000 a 2014. Revista Alcance, v.24, n.2, p258271. Disponível em Disponível em: <www.univali.br/periodicos> Acesso em 05 de fevereiro de 2018.

CENSO DEMOGRÁFICO 2010 - Características gerais da população, religião e pessoas com deficiência. Disponível em <http://www.ibge.gov.br/home/presidencia/noticias/noticia_impressao.php?id_noticia=217 $0>$. Acesso em 26/11/2017.

COX JR., T.; BLAKE, S. Managing cultural diversity: implication for organizational competitiveness. The Academy of Management Executive, v. 5, n. 3, p. 45-56, Aug.1991.

FINKELSTEIN, V. Attitudes and Disabled People: Issues for Discussion. New York, USA: International Exchange of Information in Rehabilitation, 1980.

GLASER, B. G.; STRAUSS, A. L. The discovery of grounded theory: strategies for research qualitative. New York : Aldine de Gruyter, 1967.

HEINSKI, R. M. M. S; BIGNETTI, L. P. A inclusão de pessoas portadoras de deficiência no mercado de trabalho. Cladea,. Porto Alegre. Anais eletrônicos. 2002.

HOPFER, K. R. e MACIEL-LIMA, S. M. Grounded Theory: avaliação crítica do método nos estudos organizacionais. Rev. FAE, Curitiba, v.11, n.2, p.23-24, jul./dez. 2008.

MARQUES, C. A. A construção do anormal: uma estratégia de poder. In: Encontro Anual da Associação Nacional de Pós-Graduação e Pesquisa em Educação, 24, 2001,Caxambú. Anais eletrônicos... Caxambú: $\quad$ ANPED, 2001. Disponível em <http://www.profala.com/artpsico32.htm> Acesso em 02/12/2017.

MELLO, C. M. Abordagens e procedimentos qualitativos: implicações para pesquisas em organizações. Revista Alcance, v. 21, n. 2, p. 324-349, 2014.

MOREIRA, L. B. Socialização organizacional e dinâmica identitária de pessoas com deficiência: Um estudo no Brasil e nos Estados Unidos. Dissertação de mestrado em Administração, Universidade Federal de Lavras, Lavras, MG, Brasil, 2011.

NERI, M.; PINTO, A.; SOARES, W. e COSTILLA, H. Retratos da deficiência no Brasil. Rio de Janeiro: FGV/IBRE, CPS, 2003. 
PETRINI, M. e POZZEBOM, M. Usando grounded theory na construção de modelos teóricos. Revista Gestão e Planejamento. Salvador. v. 10, n.1,p.1-18, jan./jun. 2009.

POPOVICH, P. M. et al. The assessment of attitudes toward individuals with disabilities in the workplace. The Journal of Psychology, v. 137, n. 2, p. 163-177, 2003.

QUINTÃO, D. T. R. Algumas reflexões sobre a pessoa portadora de deficiência e sua relação com o social. Psicologia e Sociedade, v. 17, n. 1, p. 17-28, jan/abr. 2005.

RELATÓRIO MUNDIAL SOBRE A DEFICIÊNCIA-2011. Secretaria de Estado dos Direitos da Pessoa com Deficiência de São Paulo. (C) Organização Mundial da Saúde - 2011. Disponível em

<http://apps.who.int/iris/bitstream/handle/10665/70670/WHO_NMH_VIP_11.01_por.pdf;js essioid=50245847C244703FDA9C0895AF161569? sequence=9> Acesso em 05 de dezembro de 2017.

REZENDE, M. G. e CARVALHO-FREITAS, M. N. Inclusão de Pessoas com Deficiência no Trabalho: Como os Profissionais de Recursos Humanos Lidam com Essa Realidade? VIII Encontro de Estudos Organizacionais da ANPAD. Gramado/RS, 25 a 27 de maio de 2014.

RIBEIRO, M. A. e CARNEIRO, R. A inclusão indesejada: as empresas brasileiras face à Lei de Cotas para pessoas com deficiência no mercado de trabalho. O\&S. Salvador, v.16, n.50, p. 545-564, julho/setembro, 2009.

SASSAKI, R. K. Vida independente: história, movimento, liderança, conceito, filosofia e fundamentos. São Paulo: RNR, 2003.

SCHWARTZ, A. e HABER, J. A ação de Recursos Humanos e a inclusão de pessoas com deficiência. Coleção Febraban de inclusão Social. Febraban (Federação Brasileira de Bancos). Agosto, 2006.

STRAUSS, A. e CORBIN, J. Pesquisa qualitativa: técnicas e procedimentos para o desenvolvimento de teoria fundamentada. Tradução: Luciane de Oliveira da Rocha. $2^{a}$ ed. Porto Alegre: Artmed, 2008.

ZANIN, E. R. M.; BACH, T. M.; WALTER, S. A. Grounded theory em estudos organizacionais: análise das metodologias, dos temas e de suas finalidades. In: SEMEAD, 15., 2012, São Paulo. Anais... São Paulo: FEA/USP, 2012. Disponível em: <http://sistema.semead.com.br/15semead/resultado/trabalhosPDF/786.pdf> Acesso em: 09 de abril de 2018.

Recebido em: 01.05.2018

Aprovado em: 04.06.2018 